\title{
IDENTIFICAÇÃO DE INOVAÇÕES NAS VINÍCOLAS DO VALE SÃO FRANCISCO SOB O OLHAR DOS CONSUMIDORES DE VINHO
}

\section{IDENTIFICATION OF INNOVATIONS IN WINERIES IN THE SÃO FRANCISCO VALLEY UNDER THE EYES OF WINE CONSUMERS}

\section{MURILO CAMPOS ROCHA LIMA}

Universidade Federal do Rio Grande do Sul (UFRGS)

Doutorando em Agronegócios (UFRGS)

Orcid: http://orcid.org/0000-0002-7891-6102/E-mail: murilocampos.86@gmail.com Av. Bento Gonçalves, 7712 - Agronomia, Porto Alegre/RS, CEP: 91540-000. Centro de Estudos e

Pesquisas em Agronegócios/CEPAN-UFRGS

\section{MARCELO COSTA BORBA}

Universidade Federal do Rio Grande do Sul (UFRGS)

Doutorando em Agronegócios (UFRGS)

Orcid: http://orcid.org/0000-0002-7173-1199/E-mail: marcelodcborba@gmail.com

\section{MARILIA ROCHA AMANDO}

Universidade do Vale do São Francisco (UNIVASF)

Mestre em Educação - Universidade de Pernambuco (UPE)

Orcid: http://orcid.org/0000-0001-6714-0946/ E-mail: marilia_amando@hotmail.com

JOSEFA EDILEIDE SANTOS RAMOS

Universidade Federal do Rio Grande do Sul (UFRGS)

Doutoranda em Agronegócios (UFRGS)

Orcid: http://orcid.org/0000-0001-7678-257X/ E-mail: edileideramos@gmail.com

Submissão: 06/12/2020. Revisão: 30/05/2021. Aceite: 25/07/2021. Publicação: 28/07/2021. DOI: http://dx.doi.org/10.22277/rgo.v14i3.5954

\section{RESUMO}

O incremento de tecnologias e de inovações vem sendo umas das fontes de desenvolvimento econômico dos países ao longo das décadas. Diante da construção contextual da temática do agronegócio e sua importância, não só para o âmbito nacional, mas também para a localidade do vale do São Francisco, percebe-se a necessidade de trabalhos empíricos que preencham lacunas de compreensão prática desta temática. O presente estudo, objetiva identificar, através das percepções dos consumidores de vinho da região, os tipos de inovações que as vinícolas locais praticam. Para alcançar o objetivo foi feito uma pesquisa do tipo exploratória, com natureza descritiva e abordagem metodológica qualitativa e quantitativa utilizando da técnica de "análise de conteúdo", com apoio da ferramenta Atlas T.I. para analisar os resultados. Sendo percebido que as viniculturas da região do Submédio do Vale do São Francisco acabam explorando o diferencial local, como clima em suas estratégias de marketing e esses discursos das vinícolas acabam sendo reproduzidos nas falas dos entrevistados desta pesquisa.

Palavras-chave: Experiências enoturísticas. Relações externas. Reposicionamento da marca.

Este é um artigo publicado em acesso aberto (Open Access) sob a licença Creative Commons Attribution, que permite uso, distribuição e reprodução em qualquer meio, sem restrições desde que o trabalho original seja corretamente citado. 
Identificação de inovações nas vinícolas do Vale São Francisco sob o olhar dos consumidores de vinho

\begin{abstract}
The increase in technologies and innovations has been one of the sources of economic development in countries over the decades. In view of the contextual construction of the theme of agribusiness and its importance, not only for the national level, but also for the locality of the São Francisco valley, there is a need for empirical works that fill gaps in the practical understanding of this theme. This study aims to identify, through the perceptions of wine consumers in the region, the types of innovations that local wineries practice. To achieve the objective, an exploratory research was carried out, with a descriptive nature and qualitative and quantitative methodological approach using the technique of "content analysis", with the support of the Atlas T.I. tool to analyze the results. It was noticed that the wineries in the sub media region of the São Francisco Valley end up exploring the local differential, such as climate in their marketing strategies and these speeches from the wineries end up being reproduced in the speeches of the interviewees of this research.
\end{abstract}

Keywords: Wine tourism experience. External relations. Brand repositioning.

\title{
1 INTRODUÇÃo
}

Nos últimos tempos, especialmente, do período compreendido entre o século XIX e o século XX, o mercado experimentou grandes transformações, sobretudo, da produção. Houve a migração do artesanal para o industrial, até sua completa automação, bem como a comercialização dessa produção. Gerando o aumento da concorrência e da competitividade provocada pelas inovações tecnológicas, mudanças comportamentais e geração de grandes fluxos de informações. A disponibilização de informações estratégicas é cada vez mais importante para o desenvolvimento de vantagem competitiva nas organizações, porém, estas possuem poucas informações relacionadas aos seus comandos internos e aos processos de tomada de decisão (MASSRUHÁ et al., 2020; MONDO; COSTA, 2010).

De acordo com um balanço apresentado pela Organização Mundial da Vinha e do Vinho (International Organisation of Vine and Wine - OIV), o consumo mundial de vinho cresceu ligeiramente em 2016, chegando aos 241 milhões de hectolitros (MARIANI; POMARICl, 2019). Ainda no balanço, a OIV apresentou dados sobre a área de produção vitivinícola, que tem impressionantes números de 7,5 milhões de hectares, nos quais cinco países são detentores de cerca de $50 \%$ da produção, quais sejam: Espanha (13\%), China (11\%), França (10\%), Itália (9\%) e Turquia (6\%). Embora o velho mundo domine as principais transações, países produtores não tradicionais, também conhecidos como vinícolas do novo mundo, têm se destacado graças a investimentos em tecnologia, marketing e inovação (ALMEIDA; BRAGAGNOLO; CHAGAS, 2015).

Este estudo foi desenvolvido no Vale do São Francisco, sertão nordestino, reconhecido nacionalmente como o maior exportador de uvas do país, exportando frutas tropicais para o mundo inteiro, principalmente para o mercado europeu. Destaca-se que, em 2017, 71,35\% da uva exportadas pelo Brasil saíram da cadeia produtiva de Petrolina, dados que vão do mês de janeiro até o mês de outubro, sendo movimentados 42,5 milhões de dólares, o que se aproxima de 20,2 milhões de quilos de uva (OUTEMANE et al., 2018). O vale do São Francisco produz cerca de 8 milhões de litros de vinho por ano, o que corresponde cerca de $15 \%$ do mercado nacional, movimentando até 1 bilhão de reais anualmente (OLIVEIRA SANTOS et al., 2020). O objeto de estudo consiste nas duas maiores vinícolas do vale do São Francisco em um universo de 12 vinícolas, no qual as duas vinícolas são responsáveis por até $50 \%$ da

RGO - Revista Gestão Organizacional, Chapecó, v. 14, n. 3, p. 132-142, set./dez. 2021. 
produção do vale, ou seja, produzem ao ano 4 milhões de garrafas de vinhos e espumantes da região.

A pesquisa tem como objetivo identificar os tipos de inovações praticadas pelas vinícolas do vale do são Francisco, sob o olhar das falas dos consumidores de vinho da região alinhando as falas aos conceitos trabalhados de inovação.

\section{REFERENCIAL TEÓRICO}

Esta seção aborda os avanços tecnológicos e de inovação como fontes de fomento para desenvolvimento de produtos, processos, marketing e organizacional. Assim como a estratégias de combinação de produtos e serviços para melhorar a relação empresa e consumidor no mercado vinícola através da análise das sensações e experiências através do vinho.

\subsection{INOVAÇÃO}

O avanço tecnológico e de inovação vem sendo umas das fontes de desenvolvimento econômico dos países ao longo das décadas. Muito esse desenvolvimento se deve ao patamar de qualificação e de educação dos colaboradores, como um dos fatores mais importantes no crescimento produtivo e de melhorias em todos os aspectos organizacionais (PORTER, 2005). Assim como, a posse das competências individuais necessárias de cada operação na organização, a empresa pode identificar potenciais inovadores (FILLOL; FELIU, 2011). E Portanto, de certa forma, a inovação tornou-se, para muitas empresas, a principal estratégia competitiva de sobrevivência e de crescimento, além da possibilidade de ter proveito das oportunidades de mercado, gerando assim, vantagens competitivas (PORTER, 2005).

No agronegócio, por haver predomínio de commodities, grande parte das organizações procuram competir no setor utilizando estratégias por baixo custo. Este fato ocasiona a necessidade de buscar novas combinações para aumentar a produção. Esse mecanismo de mudança com o objetivo de gerar vantagem competitiva para as empresas pode ser considerado uma inovação (SACRAMENTO; TEIXEIRA, 2015). Destaca-se a importância da inovação no crescimento dos negócios dada, indicando o empreendedor como sendo possuidor de um papel primordial para manter o fluxo circular do desenvolvimento econômico. Sendo assim, para ocorrer inovação, no âmbito organizacional, deve haver a combinação de materiais e forças (SCHUMPETER, 1961). A inovação também tem como o processo das organizações colocarem em prática projetos de produtos ou processos que são novos para a empresa (SCHUMPETER; LABINI, 1977). Nesta construção contextual, destacam que a gestão da inovação engloba um conjunto de estágios e decisões, configurado de uma maneira flexível diante do contexto do projeto ou da organização, desde a formatação da ideia até o desenvolvimento completo de uma oportunidade (SILVA; BAGNO; SALERNO, 2014).

$\mathrm{Na}$ perspectiva de desenvolvimento, as organizações vêm trilhando caminhos de investimentos em inovação, especialmente nas inovações que ofereçam um diferencial no seu mercado de atuação e nas suas práticas organizacionais. Assim, para que uma organização possa ser considerada inovadora quando oferta bens e serviços que não existam anteriormente, utilizando um novo método organizacional (não utilizado anteriormente), que auxilia na produção de um novo produto (não existente no mercado até então) (PELEGRIN; ANTUNES JR, 2013).

O manual de OSLO - Proposta de Diretrizes para Coleta e Interpretação de Dados sobre Inovação Tecnológica traz quatro tipos de inovação: de produto, de processo, de marketing e 
Identificação de inovações nas vinícolas do Vale São Francisco sob o olhar dos consumidores de vinho

organizacional (OSLO, 2005). Descrição de cada um destes tipos de inovação, abaixo (ECHEVARRÍA, 2008):

- Inovação de produto é a introdução de um bem ou serviço novo ou significativamente melhorado no que concerne a suas características ou usos previstos. Incluem-se melhoramentos significativos em especificações técnicas, componentes e materiais, softwares incorporados, facilidade de uso ou outras características funcionais.

- Inovação de processo é a implementação de um método de produção ou distribuição novo ou significativamente melhorado. Incluem-se mudanças significativas em técnicas, equipamentos e/ou softwares. As inovações de processo podem visar reduzir custos de produção ou de distribuição, melhorar a qualidade, ou ainda produzir ou distribuir produtos novos ou significativamente melhorados.

- Inovação de marketing é a implementação de um novo método de marketing com mudanças significativas na concepção do produto ou em sua embalagem, no posicionamento do produto, em sua promoção ou na fixação de preços. Inovações de marketing são voltadas para melhor atender as necessidades dos consumidores, abrindo novos mercados, ou reposicionando o produto de uma empresa no mercado, com o objetivo de aumentar as vendas.

- Inovação organizacional é a implementação de um novo método organizacional nas práticas de negócios da empresa, na organização do seu local de trabalho ou em suas relações externas. Inovações organizacionais podem visar a melhoria do desempenho de uma empresa por meio da redução de custos administrativos ou de custos de transação, estimulando a satisfação no local de trabalho (e assim a produtividade do trabalho), ganhando acesso a ativos não transacionáveis (como o conhecimento externo não codificado) ou reduzindo os custos de suprimentos.

E sobre inovação para as vinícolas, a inovação é a chave para as empresas desenvolverem, crescerem e se posicionarem, de forma sustentável, garantindo rentabilidade no negócio, especialmente onde há mudanças nas necessidades dos clientes (DRESSLER, 2016). E as vinícolas são caracterizadas por atividades de inovação e mudança intensivos. Mudança intensiva pode estar enraizada em efeitos bandwaggoning, sendo empurrado por tendências e modismos. Empreendedores no negócio do vinho são instados a se adaptarem às mudanças no comportamento dos clientes e a reagirem às tendências que eles consideram ser importantes (CASSOL et al., 2018). Contudo, as estratégias de marketing das vinícolas têm que levar em consideração o consumidor, como alerta o autor que, segundo ele, as vinícolas lançam luz sobre a área de comportamento estratégico do cliente, especificamente a influência de compradores prospectivos e míopes no preço e na venda da empresa, ou seja, pode-se dizer que as inovações praticadas pelas vinícolas devem considerar, também, as expectativas dos consumidores (DRESSLER, 2016).

\subsection{SENSAÇÕES E EXPERIÊNCIAS ATRAVÉS DO VINHO}

Com o intuito de agregar valor ao produto e de entregar ao consumidor experiências únicas, o mercado do vinho, cada vez mais, apresenta uma combinação de produtos e serviços para melhorar a relação empresa e consumidor. Segundo os estudos nesta área, o mercado do vinho e tudo que o envolve turismo, cultura, história, gastronomia, sensações, experiências, entre outros fatores, o faz um negócio complexo. Para entregar uma experiência única ao consumidor, as vinícolas estão entregando uma combinação de serviços atrelados 
aos produtos finais. Esses serviços passam pelos passeios turísticos, gastronômicos e degustação dos vinhos produzidos localmente.

Para isso, valorizar a identidade local, os atrativos e o que faz parte da história são aspectos capazes de proporcionar aos visitantes uma experiência que vai além do fato de conhecer um novo ambiente (TONINI; LAVANDOSKI; BARRETTO, 2012). É uma experiência que transcende diferenças em busca da satisfação de necessidades do indivíduo na atualidade. A pesquisa que o autor fez revela que "A sensação do encontro com a paisagem, o sentimento de estar degustando um vinho em vinícolas cujo conhecimento passa de geração para geração" proporcionou aos seus entrevistados só sensações positivas, como as de: alegria, prazer, emoção, paz, sonho, felicidade, bem-estar, gratificante, entre outras. Não é recomendável finalizar uma seção com uma citação de um autor. Faça um ou dois parágrafos de fechamento da seção.

\section{METODOLOGIA}

Pesquisa do tipo exploratória e abordagem metodológica qualitativa e quantitativa. Para atingir o objetivo proposto pela pesquisa, foi realizada uma investigação qualitativa, buscando descrever características do fenômeno/população na compreensão já a análise das questões objetivas possuiu caráter quantitativo. Foram utilizados como instrumento de coleta de dados questionários semiestruturados que permitiram uma análise mais detalhada da concepção dos respondentes. Os questionários foram aplicados com os consumidores das vinícolas residentes nas cidades de Petrolina/PE e Juazeiro/BA. Ao todo 57 pessoas responderam o questionário. Vale destacar que foi realizado um pré-teste do roteiro antes da execução das entrevistas para testar a adequação. Por fim, após a coleta, os dados foram transcritos para o Excel e aplicou-se o método de análise de conteúdo para observação dos resultados.

Para esta fase, foi utilizada a técnica de análise do conteúdo, um método empírico do tipo de "fala" a que se dedica e o tipo de interpretação a que se pretende com o objetivo (BARDIN, 2009). Como a pesquisa propõe analisar diversas fontes de informações, considerando alguns procedimentos para a realização de análises como essa foram definidos para serem adaptados nesta pesquisa (BARDIN, 2009):

$>$ Estabelecer uma tipologia dos materiais selecionados: considerando as categorias teóricas;

$>$ Medir a implicação política de seus discursos: procurar os sentidos de cada argumento utilizado nos discursos dos documentos primários e secundários;

D Encontrar o inconsciente coletivo: através dos questionários com os clientes das vinícolas;

A análise, seguindo um roteiro elaborado de acordo com os mecanismos propostos acima, buscou identificar os tipos de inovações praticadas pelas vinícolas da região do vale do são Francisco.

\section{ANÁLISE DOS RESULTADOS}

Além da descrição dos resultados, este estudo apresenta a análise dos mesmos, de acordo com o método da análise de conteúdo, compreendendo as etapas de: síntese dos resultados, inferência e interpretação. Para a realização da análise, foi utilizado o software Atlas T.I., o qual contribuiu no relacionamento das categorias teóricas, Inovação em Produto, Processos, Marketing e Organizacional, com a identificação dos sentidos empíricos percebidos. Na primeira questão, foi perguntado que atributos são consideravam como 
Identificação de inovações nas vinícolas do Vale São Francisco sob o olhar dos consumidores de vinho

importantes para que as vinícolas fossem consideradas de boa qualidade. A Figura 1 , fornecida pelo Atlas.ti, apresenta uma teia dos sentidos empíricos percebidos nos discursos dos clientes ao responderem a esse questionamento.

Figura 1 - Atributos de qualidades considerados pelos clientes em uma vinícola.

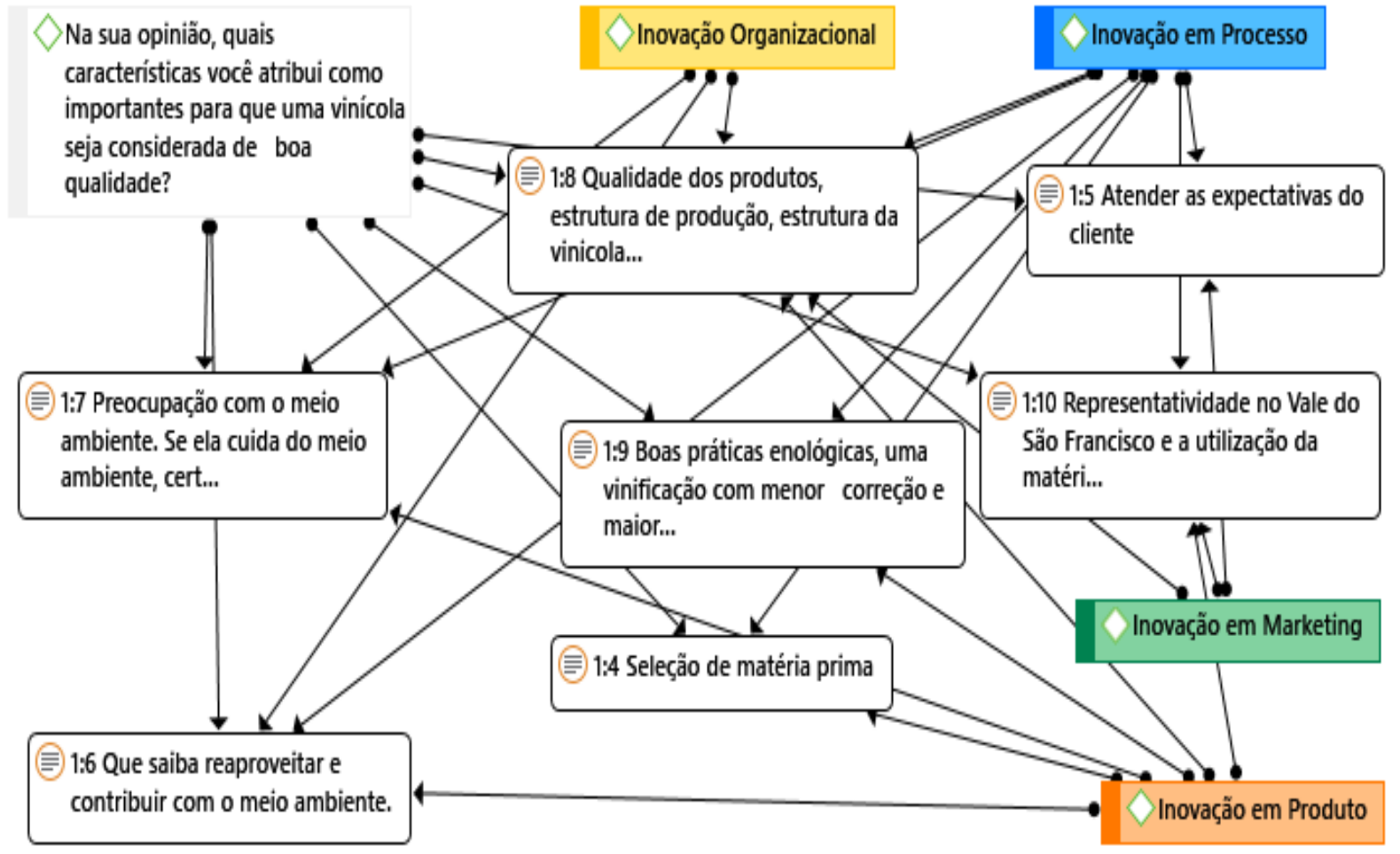

Fonte: elaborado pelos autores (2020).

Com a finalidade de conhecer mais sobre o perfil dos respondentes, a segunda pergunta foi referente à periodicidade com que os participantes costumam consumir os produtos das vinícolas. O Gráfico 1 apresenta os resultados obtidos.

Gráfico 1 - Periocidade de consumo dos produtos das vinícolas

\section{Em qual periodicidade você costuma consumir vinhos?}

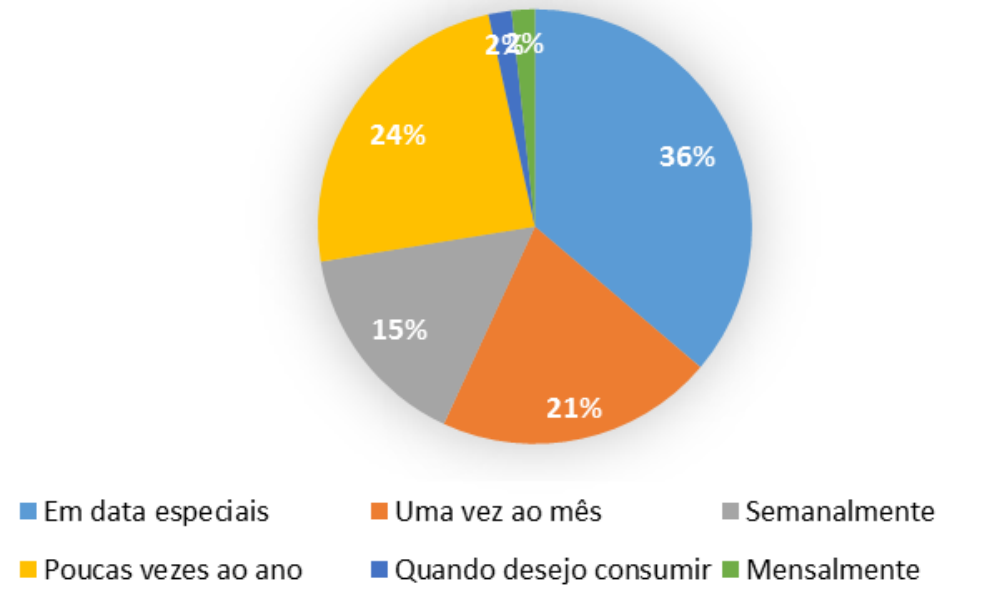

Fonte: elaborado pelos autores (2020).

Foi questionado, também, se os clientes percebiam características únicas dos vinhos oferecidos pelas vinícolas da região do vale do São Francisco. O Gráfico 2 apresenta o resultado levados em consideração. 
Gráfico 2 - Percepção de características únicas

\section{Você considera que os vinhos da região do vale do São Francisco têm características únicas?}

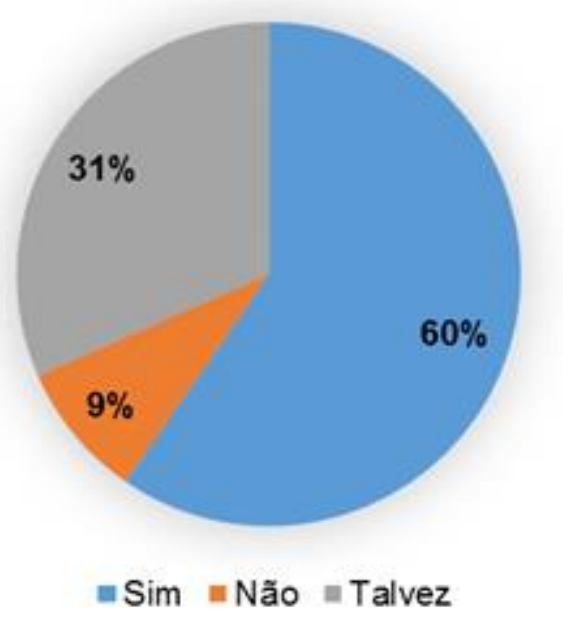

Fonte: elaborado pelos autores (2020).

Verifica-se que $60 \%$ dos entrevistados responderam sim, ou seja, percebem características únicas. Desta forma, foram também indagados sobre quais seriam estas características únicas percebidas, conforme apresenta a Figura 2.

Figura 2 - Características únicas dos produtos das vinícolas.

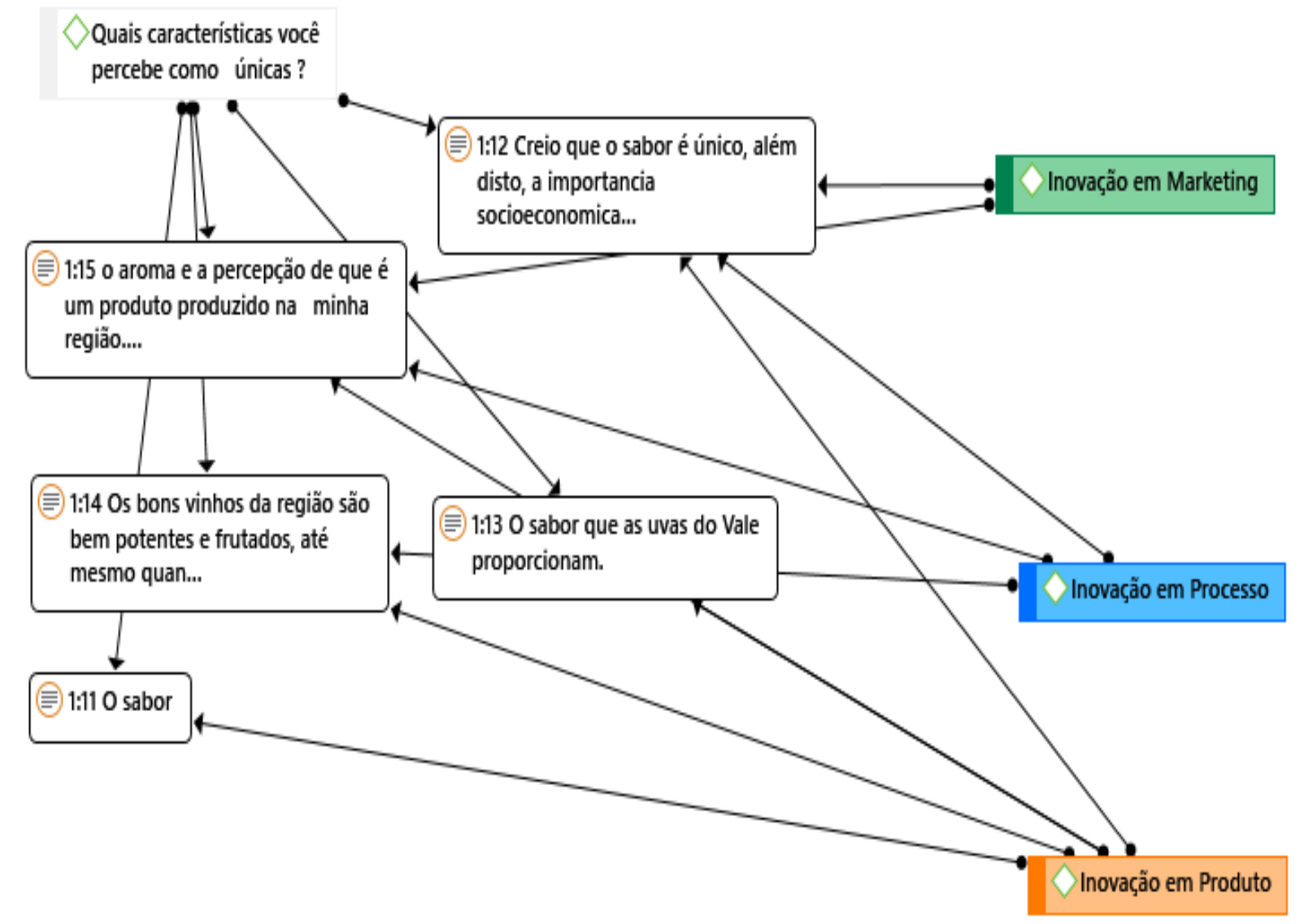

Fonte: elaborado pelos autores (2020).

Entre os sentidos percebidos, trazidos por esta teia, constatou-se elementos ligados ao Inovação em Processo, Produto e Marketing. Dentro da categoria "Produto", foi percebida 
Identificação de inovações nas vinícolas do Vale São Francisco sob o olhar dos consumidores de vinho

nas falas dos clientes, pelas citações como fator "único" das vinícolas, identificada nas quotas: "Tipo e periocidade das uvas" e "Sabor", estas duas falas, são vistas como fatores únicos dos produtos das vinícolas da região, ou seja, que diferem de outras vinícolas. Quanto a categoria "Marketing" teve como fator único dos produtos das vinícolas atribuída ao "Regionalismo", percebida através das quotas "Autenticidade de ser produzido no vale do São Francisco", "A região de produção", "produzido na minha região". E a quota: "a importância socioeconômica da uva na região" remete à categoria "Marketing", ligado também ao "Regionalismo", mas apresentando a sensação percebida de importância socioeconômica da uva para a região, apresentando como se esse fator fosse uma característica única dos produtos das vinícolas da região.

Com o intuito de identificar, de acordo com a percepção dos respondentes, o que é apresentado nos passeios às vinícolas, foram questionados objetivamente: "o que foi apresentado no passeio?". Diante disto, foram identificadas algumas categorias teóricas, com incidência maior para "Produto", como pode ser verificado na Figura 3.

Figura 3 - O que foi apresentado nos passeios às vinícolas.

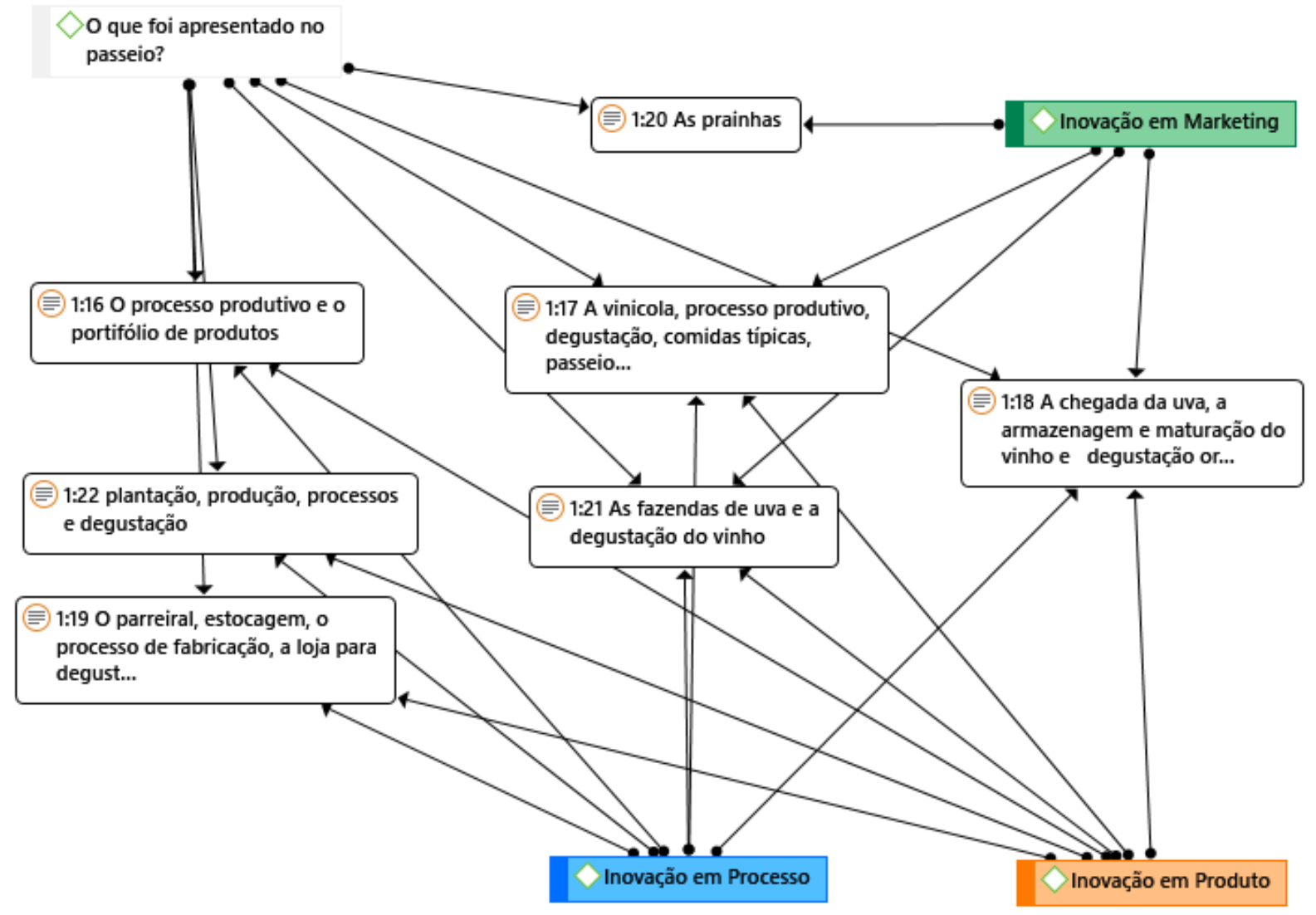

Fonte: elaborado pelos autores (2020).

Através da teia apresentada na Figura 3 verifica-se que há nos passeios um tempo designado para tratar do processo de produção dos vinhos e, a academia cientifica trata os passeios nas vinícolas como estratégias de marketing, os passeios são vistos estrategicamente, pois possibilitam a geração de mais conhecimento, desde o processo de produção do vinho, aos tipos de vinho, como também o fornecimento de experiências ao cliente relacionadas à região produtora dos vinhos, assim, oportunizando uma aproximação do cliente à marca da vinícola. Finalizando, foi solicitado aos participantes resumirem em uma única palavra as vinícolas da região do vale do São Francisco, o resultado deste questionamento pode ser conferido na Figura 4: 
Figura 4 - Resumo em uma palavra às vinícolas da região.

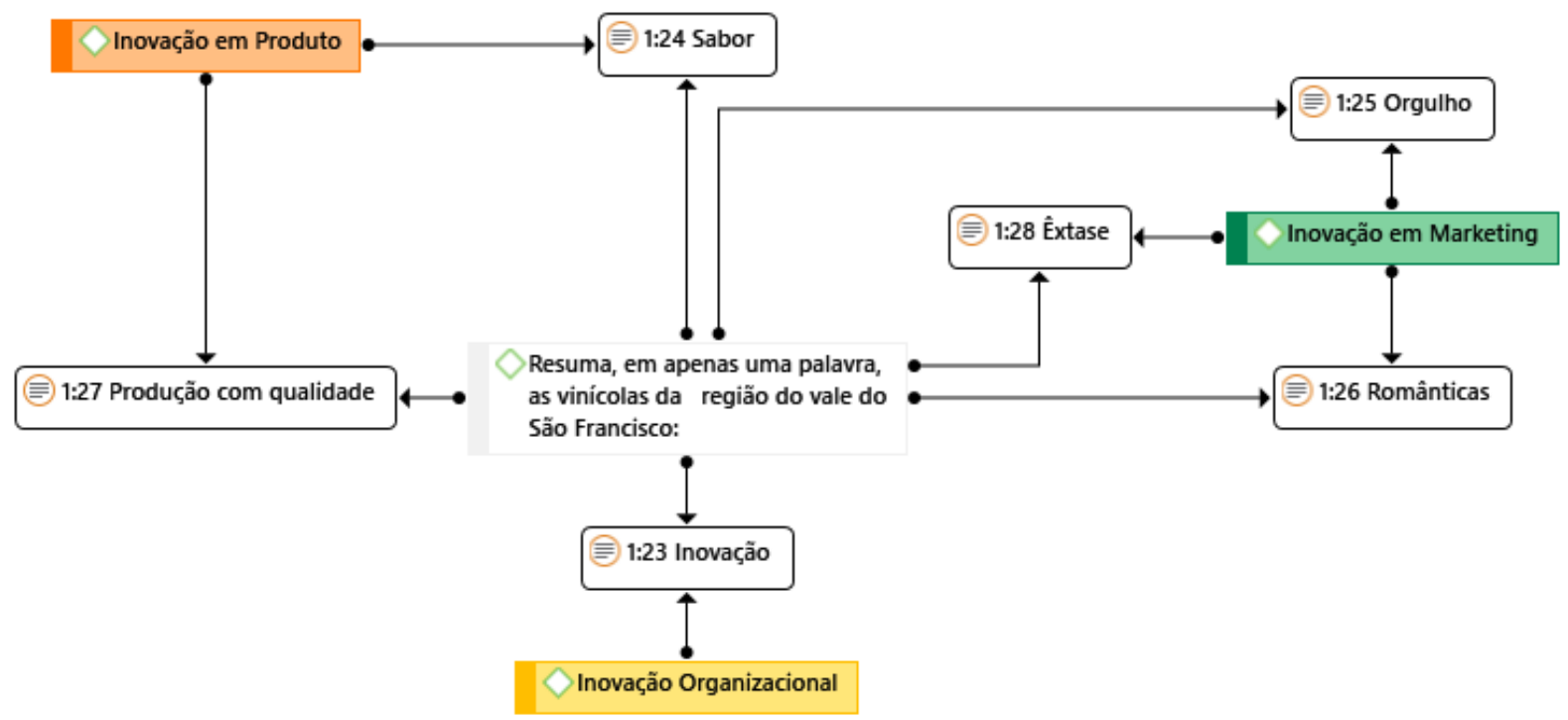

Fonte: elaborado pelos autores (2020).

A partir da análise, foi possível verificar que todas as categorias teóricas foram identificadas nos discursos dos respondentes, além disso, importa frisar que as percepções dos mesmos se correlacionavam, muitas vezes, na mesma fala, intersecções abordadas na Tabela 1.

Tabela 1 - Intersecção das subcategorias teóricas.

\begin{tabular}{l|c|c|c|c}
\hline CORRELAÇÃO & $\begin{array}{l}\text { Inovação em } \\
\text { Marketing }\end{array}$ & $\begin{array}{l}\text { Inovação em } \\
\text { Processo }\end{array}$ & $\begin{array}{l}\text { Inovação em } \\
\text { Produto }\end{array}$ & $\begin{array}{l}\text { Inovação } \\
\text { Organizacional }\end{array}$ \\
\hline $\begin{array}{l}\text { Inovação em } \\
\text { Marketing }\end{array}$ & 0 & 8 & 7 & 1 \\
\hline $\begin{array}{l}\text { Inovação em } \\
\text { Processo }\end{array}$ & 8 & 0 & 15 & 3 \\
\hline $\begin{array}{l}\text { Inovação em Produto } \\
\text { Inovação } \\
\text { Organizacional }\end{array}$ & 7 & 15 & 0 & 3 \\
\hline
\end{tabular}

Fonte: elaborado pelos autores (2020).

De modo geral, agregando-se os resultados das subcategorias em suas categorias correspondentes, a Tabela 2 apresenta quantas vezes as categorias teóricas foram percebidas pelos entrevistados, contexto em que "Produto" foi a mais percebida pelos clientes.

Tabela 2 - Quantidade de quotas para cada categoria teórica

\begin{tabular}{c|c|c|c|c}
\hline $\begin{array}{c}\text { Categorias } \\
\text { Teóricas }\end{array}$ & Produto & Processo & Organizacional & Marketing \\
\hline Quotas & 19 & 16 & 4 & 12 \\
\hline Total: & & & 51 & \\
\hline
\end{tabular}

Fonte: elaborado pelos autores (2020).

\section{CONSIDERAÇÕES FINAIS}

A pesquisa teve como objetivo identificar os tipos de inovações praticadas pelas vinícolas do vale do são Francisco, sob o olhar das falas dos consumidores de vinho da região, alinhando as falas aos conceitos trabalhados de inovação. $E$ foi percebido que na fala dos 57 
Identificação de inovações nas vinícolas do Vale São Francisco sob o olhar dos consumidores de vinho

entrevistados pode-se inferir que as vinícolas da região trabalham estrategicamente os pontos da inovação que o manual de OSLO aborda: Inovação em produto, processo, marketing e organizacional.

O ponto mais perceptível pelos clientes é do produto, já o menos perceptível corresponde ao fator organizacional, isso está relacionado provavelmente ao cliente está mais próximo do produto final do que internamente na organização. Mas mesmo com esse distanciamento, alguns clientes retrataram a importância de a organização ter uma estrutura interna favorável para ter qualidade, esses pontos podem ser inferidos à categoria de inovação organizacional.

Lembrando que o presente estudo buscou identificar os tipos de inovações que são praticadas pelas vinícolas sob o olhar do cliente, logo o resultado não significa necessariamente que as vinícolas inovaram nas quatros categorias debatidas. Para isso o presente estudo sugere, para próximas pesquisas, fazer o levantamento em conjunto com as vinícolas da região, complementando o atual estudo, com intuito de identificar os tipos de inovação praticadas pelas vinícolas e se encontram com as falas, percepções, dos clientes respondentes desta pesquisa.

\section{NOTA}

O artigo foi indicado no fast track do VIII Simpósio da Ciência do Agronegócio 2020.

\section{REFERÊNCIAS}

ALMEIDA, A. N.; BRAGAGNOLO, C.; CHAGAS, A. L. S. A Demanda por vinho no Brasil : elasticidades no consumo das famílias e determinantes de importação. Revista de Economia e Sociologia Rural, v. 53, n. 03, p. 433-454, 2015.

BARDIN, L. Análise de conteúdo. Lisboa: Edições, v. 70, 2009.

CASSOL, A. NOVAKOWSKI, B. F. D.; TONIAL, G.; DALBOSCO, I. B. Estratégias de internacionalização de pequenas e médias empresas: estudo multicasos. Revista Gestão Organizacional, v. 10, n. 3, p. 55-78, 2018.

DRESSLER, M. Strategic winery reputation management-exploring German wine guides. International Journal of Wine Business Research, 2016.

ECHEVARRÍA, J. El manual de Oslo y la innovación social. Arbor, v. 184, n. 732, p. 609-618, 2008.

FILLOL, A. G.; FELIU, V. M. R. Análisis de la gestión por procesos y por competencias a través de la perspectiva de procesos y de aprendizaje y crecimiento: la experiencia de la autoridad portuaria de Valencia. Revista Universo Contábil, v. 7, n. 2, p. 114-129, 2011.

MARIANI, A.; POMARICI, E. Barriers to wine trade BT - The palgrave handbook of wine industry economics. In: ALONSO UGAGLIA, A.; CARDEBAT, J.-M.; CORSI, A. (Eds.). . Cham: Springer International Publishing, 2019. p. 291-315. 
MASSRUHÁ, S. M. F. S.; LEITE, M. A. A.; OLIVEIRA, S. R. M.; MEIRA, C. A. A.; LUCHIARI JUNIOR, A.; BOLFE, E. L. Agricultura digital: pesquisa, desenvolvimento e inovação nas cadeias produtivas. Brasília: Embrapa, 2020.

MONDO, T. S.; COSTA, J. I. P. Estratégias de marketing das vinícolas catarinenses. Revista Gestão Organizacional, v. 3, n. 2, p. 163-181, 2010.

SANTOS, M. A.; TORRES, M. B.; SIQUEIRA, L. P.; PONTES NETO, J. G. Análise físico-química de vinhos: um comparativo entre os vinhos do vale do São Francisco no Brasil e os vinhos do douro em Portugal. Brazilian Journal of Development, v. 6, n. 11, p. 85354-85371, 2020.

OSLO. The measurement of scientific and technological activities. Proposed Guidelines for Collecting an Interpreting Technological Innovation Data, v. 30, 2005.

OUTEMANE, M.; WURZ, D.A.; BEM, B.P.; ALLEBRANDT, R.; CANOSSA, A.T.; REINEHR, J.; CECHETTO, M.; COMACHIO, L., KRETZSCHMAR, A. A. Panorama de comercialização de vinhos finos e de mesa no Brasil. Revista Uniplac, v. 6, n. 1, 28 fev. 2018.

PELEGRIN, I.; ANTUNES JR, J. A. V. Inovação: uma discussão conceitual a partir da perspectiva da cadeia de valor. Gestão da inovação e competitividade no Brasil: da teoria à prática. Porto Alegre: Bookman, 2013.

PORTER, M. E. Estratégia competitiva: técnicas para a análise da indústria e da concorrência. 11. ed. Rio de Janeiro: Campus, 2005.

SACRAMENTO, P. M.; TEIXEIRA, R. M. Tipos de inovações em pequenas e médias empresas turísticas. Race: revista de administração, contabilidade e economia, v. 14, n. 1, p. 383-404, 2015.

SCHUMPETER, J. A. The theory of economic developments: an inquiry into profits, capital, credit, interest, and the business cycle. [s.I.] Harvard University Press, 1961.

SCHUMPETER, J. A.; LABINI, P. S. Teoria dello sviluppo economico. [s.I.] Sansoni Firenze., 1977.

SILVA, D. O.; BAGNO, R. B.; SALERNO, M. S. Modelos para a gestão da inovação: revisão e análise da literatura. Production, v. 24, n. 2, p. 477-490, 2014.

TONINI, H.; LAVANDOSKI, J.; BARRETTO, M. Public policy and wine tourism: master plan in vale dos vinhedos, south Brazil. Tourism \& Management Studies, p. 829-838, 2012. 